\title{
The Impact of COVID-19 on the Status of RMB as an Anchor Currency
}

\author{
Xing Fang ${ }^{1}$, Weijuan Cao ${ }^{1}$ \\ 1 School of Finance, Capital University of Economics and Business, China \\ Keywords: covid-19, anchor currency, the belt and road \\ 10.46557/001c.21439
}

\section{Asian Economics Letters}

Vol. 2, Issue 1, 2021

In the context of a severely volatile global financial market in 2020, the Ren Min Bi (RMB) has also experienced dramatic fluctuations. We examine the impact of the COVID-19 pandemic on the status of the RMB as an anchor currency in countries along the "The Belt and Road". The results show that the pandemic has caused a continuous adverse impact on the anchor role of the RMB.

\section{Introduction}

In this paper we examine the impact of the COVID-19 pandemic on the status of the Ren Min Bi (RMB) as an anchor currency. Our hypothesis is that COVID-19 has exerted a continuous adverse impact on the RMB as an anchor currency. This hypothesis is proposed based on the performance of the RMB exchange rate and is motivated by the theory of market sentiment, according to which, a major shock would cause panic in the market. The foreign exchange market will be amongst the first to be affected, thus will experience heightened exchange rate fluctuations. This hypothesis test is important because it will help to study how to promote and facilitate the steady internationalization of RMB.

Based on the recent literature, it is found that COVID-19 has influenced the capital market (see Padhan \& Prabheesh, 2021; Phan \& Narayan, 2020; Sha \& Sharma, 2020; Sharma \& Sha, 2020). The outbreak of COVID-19 not only dealt a heavy blow to the stock market, but also had a temporary impact on the exchange rate (see Iyke, 2020; Narayan, 2020). Exchange rate is a statistically significant determinant of stock market returns, and during the COVID-19 pandemic, the role of the exchange rate has become stronger (see Iyke \& Ho, 2021; Narayan et al., 2020). Iyke (2020) uses the total number of infections per million people as a measure of COVID-19 information and shows that COVID-19 contains important information that can enhance exchange rate return and volatility predictions. However, the main contribution of this paper, is to study from a new perspective whether COVID-19 will have an impact on the status of RMB as an anchor currency.

The current global trading and geopolitical environment has revealed both opportunities and challenges for the RMB as an "invisible anchor". The "oil price war" of April 2020 has driven some oil exporting countries to actively seek al- ternatives to the United States dollar as new settlement currencies. China, as the largest oil consumer in the world, may have a greater influence on oil pricing. Overall, the RMB reacted negatively during the early stages of the outbreak particularly driven by the negative sentiment that the outbreak started from China. In the mid-to-late January and February 2020, when the pandemic was rampant in China, the U.S. dollar rose, indicating that the status of U.S. dollar as a conventional safe-haven currency will not be easily challenged.

In general, the impact of the pandemic on the status of the RMB as an anchor currency is uncertain. Based on data from countries along the "The Belt and Road", we find that a negative impact exists. Our contribution to the literature is precisely in testing the effects of the COVID-19 pandemic on the currency anchor status of the RMB, which is very important to the internationalization of the RMB.

\section{Empirical Methodology and Data A. Empirical Methodology}

In order to measure the actual impact of the pandemic on the RMB's status as a currency anchor in the region along "The Belt and Road", we implement a regression based on the classic model of Frankel \& Wei (1992, 2008). Our preliminary model is as follows:

$$
\begin{aligned}
L Y_{t}= & \alpha_{0}+\alpha_{1} L E U R_{t}+\alpha_{2} L J P Y_{t} \\
& +\alpha_{3} L G B P_{t}+\alpha_{4} L U S D_{t}+\alpha_{5} L C N Y_{t}+\mu_{t}
\end{aligned}
$$

In the above equation, $L Y_{t}$ is the exchange rate of the currencies of countries along "The Belt and Road" with reference to the Swiss franc after logarithmic difference in the period $t$, and $L E U R_{t}, L J P Y_{t}, L G B P_{t}, L U S D_{t}$ and $L C N Y_{t}$ are, respectively, the exchange rate of Euro, Japanese Yen, British Pound, the U.S. Dollar and the RMB vis-a-vis the Swiss Franc after logarithmic difference in the period $t$. Therefore, $\alpha_{1}-\alpha_{5}$ are the weight of the five Special Draw- 
ing Rights (SDR) currencies in the currency basket of countries along "The Belt and Road", and $\mu_{t}$ is the random disturbance term.

Since there are other SDR reserve currencies in the currency basket officially recognized by $\mathrm{RMB}$, to avoid multicollinearity, the method of Balasubramaniam et al. (2011) is used here to run the following auxiliary regression of RMB:

$$
\begin{aligned}
L C N Y_{t}= & \beta_{0}+\beta_{1} L E U R_{t}+\beta_{2} L J P Y_{t} \\
& +\beta_{3} L G B P_{t}+\beta_{4} L U S D_{t}+e_{t}
\end{aligned}
$$

In the above equation, the residual $e_{t}$ of the auxiliary regression is the part of the RMB exchange rate that is not affected by other SDR reserve currencies, and the residual estimated value $\hat{e}_{t}$ is used to replace $L C N Y_{t}$ in formula (1), then the model is further expanded to:

$$
\begin{aligned}
L Y_{t}= & \alpha_{0}+\alpha_{1} L E U R_{t}+\alpha_{2} L J P Y_{t} \\
& +\alpha_{3} L G B P_{t}+\alpha_{4} L U S D_{t}+\alpha_{5} \hat{e}_{t}+\mu_{t}
\end{aligned}
$$

Finally, we use total cases per million (TCPM) as a COVID-19 indicator to measure the severity of the pandemic in each country. We add an interaction term between TCPM and $\hat{e}_{t}$ in the model, and the final model is:

$$
\begin{aligned}
L Y_{t}= & \alpha_{0}+\alpha_{1} L E U R_{t}+\alpha_{2} L J P Y_{t}+\alpha_{3} L G B P_{t} \\
& +\alpha_{4} L U S D_{t}+\alpha_{5} \hat{e}_{t}+\delta T C P M_{t} * \hat{e}_{t}+\mu_{t}
\end{aligned}
$$

In Equation (4), we need to pay attention to the interaction coefficient $\delta$. If $\delta$ is significantly positive, it means that the currency anchor status of the RMB in the country has risen after the pandemic; however, if $\delta$ is significantly negative, the pandemic exerts an adverse effect on the RMB anchor effect, and the weight of the RMB in the country's currency basket is declining.

\section{B. Data Description}

The sample countries are selected from 65 countries along "The Belt and Road" as specified in the document of the Ministry of Commerce of China. After excluding those with missing data or that failed the unit root test for the residual series, data for 40 countries were finally obtained for use in the basic regression, and data for 42 countries for use in the robustness test.

The sample data of exchange rates have been retrieved from the Standard \& Poor's database, and the statistics related to the pandemic have been extracted from the John Hopkins Coronavirus Resource Center. The selected interval of the exchange rate sample data is consistent with the interval of the TCPM data for each country.

\section{Result analysis \\ A. The trends of USD/CNY and USDX}

The trends of exchange rate can inform us of some patterns. We first compare the trends of the onshore RMB and the U.S. dollar index, and briefly analyze the impact of COVID-19 on the status of the anchor currency of RMB. Figure 1 plots the development trends of the onshore RMB and the U.S. dollar index. The two-way fluctuations of the USD/ CNY is obvious. When the pandemic initially broke out in China, the sensitivity of the foreign exchange market raised pressure on the exchange rate, and the RMB showed an obvious trend of depreciation. By comparison, the U.S. dollar rose sharply in March 2020, driving other currencies to depreciate under pressure. Afterwards, as China took effective

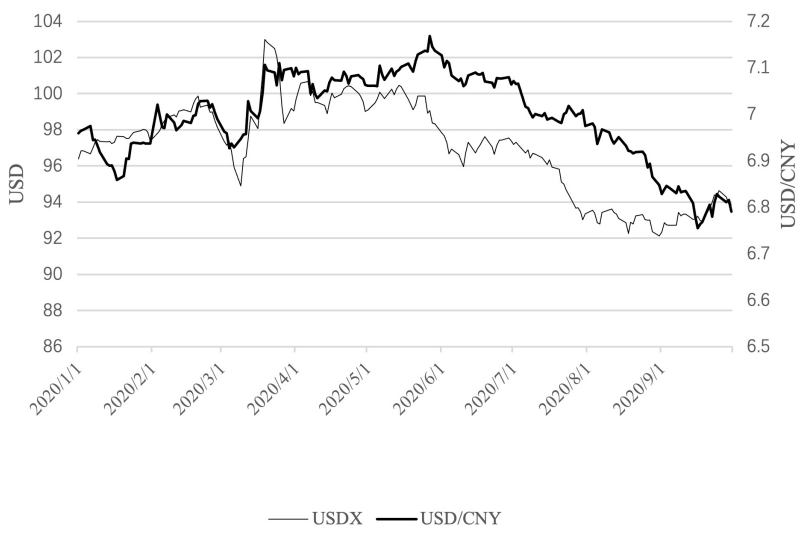

\section{Figure 1: The trends of USD/CNY and USDX}

This figure plots the trends of the onshore RMB and the U.S. dollar index. The data is daily and covers the sample period from $01 / 01 / 2020$ to $07 / 10 / 2020$ for a total of 202 observations.

measures in prevention and control, the economy rebounded, and investors purchased a large volume of RMB bonds for risk aversion. At the same time, the U.S. dollar weakened and the RMB began to appreciate continuously after June 2020. Figure 1 shows that the RMB is appreciating.

\section{B. Stationarity test}

The results of unit root tests on the exchange rates and the TCPM data of each country show that not all time series reject the hypothesis that there is no unit root. Only the first-order difference of the sampled data show that all the time series can reject the null hypothesis at the $10 \%$ level of significance.

\section{Results}

On the basis of the classic model of Frankel \& Wei, we further add the interaction term between TCPM and RMB exchange rate changes to measure the impact of the COVID-19 pandemic on the status of the RMB as an anchor currency in the "The Belt and Road" region. See Table 1 for the regression results.

With respect to the impact of the pandemic on the status of the RMB as an anchor currency, the regression results show that under the impact of COVID-19, RMB's currency anchor status has declined in 22 countries, compared to only 7 countries where the weight of RMB has increased in their currency basket. This shows that the outbreak of the COVID-19 has caused a continuous negative impact on the status of the RMB as an anchor currency in the countries along the "The Belt and Road".

The samples from each country are regressed again using the TDPM data as a COVID-19 indicator. According to the results, the number of countries where the impact of the COVID-19 reduces the status of the RMB as an anchor currency in them halves to 11 countries. The reason might be that the TDPM data appeared later, when China was getting the pandemic under control and its economic performance improved. Therefore, the countries might have increased their confidence in China and the RMB. 
Table 1: Basic regression results

\begin{tabular}{|c|c|c|c|c|c|c|c|c|}
\hline Country & LEUR & LJPY & LGBP & LUSD & LCNY & TCPM*LCNY & R-squared & ADF value of residual sequence \\
\hline Mongolia & $-0.3812^{* * *}$ & -0.0026 & 0.0373 & $1.2299^{* * *}$ & $0.4050^{* *}$ & $-0.0053^{* *}$ & 0.9887 & -4.951 \\
\hline Singapore & $0.7072^{* * *}$ & $0.1463^{* * *}$ & $0.3544^{* * *}$ & $0.4898^{* * *}$ & $0.4423^{* * *}$ & $-0.0002^{* * *}$ & 0.9195 & -3.347 \\
\hline Malaysia & $0.5177^{* * *}$ & $-0.1103^{* *}$ & $0.5034^{* * *}$ & $0.6253^{* * *}$ & $2.8891^{* * *}$ & $-2.4047^{* *}$ & 0.9409 & -5.087 \\
\hline Myanmar & $0.5170^{* * *}$ & $0.4068^{* * *}$ & $-0.3547^{* * *}$ & $0.1890^{* *}$ & $0.7412^{* * *}$ & $0.0070^{* * *}$ & 0.7176 & -4.191 \\
\hline Laos & $-0.2380^{* * *}$ & $-0.1353^{* *}$ & $0.1227^{* * *}$ & $1.2238^{* * *}$ & 0.3474 & $-0.2009^{*}$ & 0.993 & -5.027 \\
\hline Cambodia & $-0.2326^{* * *}$ & -0.0342 & 0.0036 & $0.9993^{* * *}$ & $0.5585^{* * *}$ & $-0.0440^{* * *}$ & 0.9751 & -6.092 \\
\hline Vietnam & $0.3132^{* * *}$ & -0.0256 & 0.0083 & $0.9761^{* * *}$ & $0.2519^{* * *}$ & $-0.0284^{* * *}$ & 0.9819 & -3.249 \\
\hline Brunei & $0.5318^{* * *}$ & $0.2126^{* * *}$ & $0.0980^{* * *}$ & $0.4141^{* * *}$ & $-1.4727^{* *}$ & $0.0050^{* *}$ & 0.8572 & -3.116 \\
\hline Philippines & $0.2290^{* *}$ & $-0.2165^{* *}$ & 0.0111 & $0.6035^{* * *}$ & $-0.3621^{* *}$ & $0.0004^{* * *}$ & 0.7409 & -3.903 \\
\hline India & 0.2825 & $-0.3648^{* * *}$ & $0.5669^{* * *}$ & $1.0136^{* * *}$ & $1.4014^{* * *}$ & $-0.0001^{* *}$ & 0.9248 & -3.834 \\
\hline Pakistan & $0.4886^{*}$ & $0.9864^{* * *}$ & 0.0578 & $0.9351^{* * *}$ & $2.6359^{* * *}$ & $-0.0019^{* * *}$ & 0.8695 & -3.155 \\
\hline Bangladesh & $0.0204^{* * *}$ & 0.0011 & $-0.0056^{*}$ & $0.9840^{* * *}$ & $0.0499^{* * *}$ & $-0.0002^{* * *}$ & 0.9998 & -7.012 \\
\hline Afghanistan & $-0.3132^{* * *}$ & $0.1129^{* * *}$ & $0.0490^{* *}$ & $0.9390^{* * *}$ & $0.5805^{* * *}$ & $-0.0004^{* * *}$ & 0.9865 & -5.505 \\
\hline Sri Lanka & $0.9753^{* * *}$ & -0.0344 & $0.2543^{* * *}$ & $0.9945^{* *}$ & $1.3627^{* * *}$ & $-0.0095^{* * *}$ & 0.8185 & -3.214 \\
\hline Turkey & 0.3522 & -0.7282 & $-0.4400^{* *}$ & $2.6638^{* * *}$ & 0.7753 & $-0.0011^{* *}$ & 0.8805 & -5.212 \\
\hline Syria & $-12.7223^{* * *}$ & $-13.1665^{* * *}$ & $5.8351^{* * *}$ & $23.5735^{* * *}$ & $-30.2172^{* * *}$ & $0.2036^{* * *}$ & 0.8682 & -3.889 \\
\hline Jordan & -0.0047 & $0.0168^{*}$ & -0.0035 & $0.9939^{* * *}$ & $0.0181^{* * *}$ & $-0.0003^{*}$ & 0.9997 & -9.807 \\
\hline Israel & $0.6761^{* * *}$ & $-0.3160^{* *}$ & $0.5176^{* * *}$ & $0.7626^{* * *}$ & $-1.0303^{* * *}$ & $0.0004^{*}$ & 0.5662 & -2.894 \\
\hline Bahrain & 0.005 & -0.0001 & $0.0138^{* * *}$ & $0.9748^{* * *}$ & $0.0430^{* *}$ & $-1.42 e-06^{* *}$ & 0.9991 & -6.208 \\
\hline Yemen & $-0.1160^{* *}$ & -0.0795 & $0.1829^{* * *}$ & $0.9459^{* * *}$ & $-0.3963^{* * *}$ & $0.0079^{* * *}$ & 0.9856 & -8.228 \\
\hline Kuwait & $0.4476^{* * *}$ & $0.2342^{* * *}$ & $0.0669^{* *}$ & $0.7272^{* * *}$ & $0.4644^{* * *}$ & $-0.0002^{* * *}$ & 0.9635 & -2.656 \\
\hline Kazakhstan & $1.4580^{* * *}$ & 0.0088 & $0.4421^{* * *}$ & $1.3130^{* * *}$ & $-3.9509^{* * *}$ & $0.0004^{* * *}$ & 0.6992 & -3.279 \\
\hline Tajikistan & $-0.0586^{* * *}$ & $0.0250^{* *}$ & $0.0656^{* * *}$ & $1.0397^{* * *}$ & $0.0719^{* * *}$ & $-0.0001^{*}$ & 0.999 & -3.118 \\
\hline Uzbekistan & $-0.5399^{*}$ & $-0.6784^{* *}$ & $-0.3493^{* *}$ & $1.7393^{* * *}$ & $1.5017^{* * *}$ & $-0.0013^{* * *}$ & 0.887 & -3.631 \\
\hline Belarus & $2.5689^{* * *}$ & $2.7361^{* * *}$ & 0.0178 & $0.1428^{* * *}$ & $3.9874^{*}$ & $-0.0010^{* * *}$ & 0.7871 & -2.772 \\
\hline Poland & $1.7636^{* * *}$ & $0.5335^{* * *}$ & 0.0643 & -0.6152 & $1.0870^{* * *}$ & $-0.0012^{* * *}$ & 0.8296 & -2.876 \\
\hline Croatia & $1.1939^{* * *}$ & $0.1156^{* *}$ & $0.0651^{* *}$ & $-0.1901^{* * *}$ & $0.3731^{* * *}$ & $-0.0002^{* * *}$ & 0.9333 & -3.612 \\
\hline Romania & $0.9626^{* * *}$ & $0.0375^{*}$ & $0.0650^{* * *}$ & $-0.0320^{* * *}$ & $0.1480^{* * *}$ & $-0.0008^{* * *}$ & 0.9796 & -4.125 \\
\hline
\end{tabular}

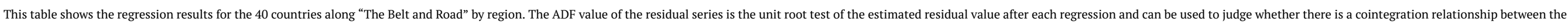
explanatory variable and the explained variable. Due to space limitations, we only show countries with significant results. *, **, and **** denote statistical significance at the $10 \%, 5 \%$, and $1 \%$ levels, respectively. 


\section{Conclusion}

In this note, we empirically test the impact of the COVID-19 pandemic on the status of the RMB as an anchor currency in the "The Belt and Road" region. The empirical results show that the pandemic has a continuous adverse effect on the anchor effect of the RMB in the "The Belt and Road" region. However, as the world regains its confidence in China, the demand for RMB assets would increase and the adverse impact is expected to diminish. Since the RMB is still on the rise, research can be conducted in the future to examine whether the negative impact of the pandemic on the status of the RMB as an anchor currency could possibly be reversed.

\section{Acknowledgment}

Helpful comments and suggestions from an anonymous reviewer of this journal helped improve the paper. The usual disclaimer applies. We acknowledge the funding by the Beijing Municipal Education Commission (Project code: SM201110038008).

Submitted: February 13, 2021 AEDT, Accepted: March 10, 2021

AEDT 


\section{REFERENCES}

Balasubramaniam, V., Patnaik, I., \& Shah, A. (2011). Who cares about the Chinese yuan? Working Papers. $\underline{\mathrm{h}}$ ttps://nipfp.org.in/media/medialibrary/2013/04/wp_2 011_89.pdf

Frankel, J. A., \& Wei, S.-J. (1992). Yen bloc or dollar bloc: Exchange rate policies of the east Asian economies. Pacific Basin Working Paper Series. htt p://www.nber.org/chapters/c8537

Frankel, J. A., \& Wei, S.-J. (2008). Estimation of de facto exchange rate regimes: Synthesis of the techniques for inferring flexibility and basket weights. IMF Staff Papers, 55(3), 384-416. https://doi.org/10.3 $\underline{386 / w 14016}$

Iyke, B. N. (2020). The Disease Outbreak Channel of Exchange Rate Return Predictability: Evidence from COVID-19. Emerging Markets Finance and Trade, 56(10), 2277-2297. https://doi.org/10.1080/1540496 $\underline{\mathrm{x} .2020 .1784718}$

Iyke, B. N., \& Ho, S.-Y. (2021). Exchange rate exposure in the South African stock market before and during the COVID-19 pandemic. Finance Research Letters, 102000. https://doi.org/10.1016/i.frl.2021.102 000

Narayan, P. K. (2020). Has COVID-19 Changed Exchange Rate Resistance to Shocks? Asian Economics Letters, 1(1). https://doi.org/10.46557/001c.17389
Narayan, P. K., Devpura, N., \& Wang, H. (2020). Japanese Currency and Stock Market-What Happened during the COVID-19 Pandemic? Economic Analysis and Policy, 68, 191-198. https://doi.org/10.1016/i.ea p.2020.09.014

Padhan, R., \& Prabheesh, K. P. (2021). The economics of COVID-19 pandemic: A survey. Economic Analysis and Policy, 70, 220-237. https://doi.org/10.1016/j.ea p.2021.02.012

Phan, D. H. B., \& Narayan, P. K. (2020). Country responses and the reaction of the stock market to COVID-19-a Preliminary Exposition. Emerging Markets Finance and Trade, 56(10), 2138-2150. http s://doi.org/10.1080/1540496x.2020.1784719

Sha, Y., \& Sharma, S. S. (2020). Research on Pandemics Special Issue of the Journal Emerging Markets Finance and Trade. Emerging Markets Finance and Trade, 56(10), 2133-2137. https://doi.org/10.108 0/1540496x.2020.1795467

Sharma, S. S., \& Sha, Y. (2020). Part A: Special Section on COVID-19 Research. Emerging Markets Finance and Trade, 56(15), 3551-3553. https://doi.or $\mathrm{g} / 10.1080 / 1540496 x .2020 .1858617$ 